\title{
Direito à saúde na sociedade contemporânea: convergência entre o público e o privado
}

\section{Right to health in contemporary society: convergence between public and private}

\author{
Vera Maria Ribeiro Nogueira ${ }^{a}$
}

\begin{abstract}
Resumo
Este artigo discute os direitos sociais na sociedade atual. Parte-se do suposto que a compreensão dos direitos sociais e do direito à saúde ocorre em várias clivagens e somente pode ser abordado como um processo histórico, determinado em cada sociedade a partir das relações estabelecidas entre as classes sociais. Evidencia como, no campo da saúde, especialmente o relacionado às políticas públicas de saúde, apreender o significado da amplitude do direito determina questões de vida ou morte, sendo um aspecto essencial para inferir o grau de inclusão ou exclusão de parcelas da população a um atendimento universal e gratuito.
\end{abstract}

Palavras-chave: direito à saúde, direito social, cidadania, universalização, política social.

\begin{abstract}
This article discusses social rights in today's society. It starts from the assumption that the understanding of social rights and the right to health occurs in several cleavages and can only be approached as a historical process, determined in each society from the relations established between social classes. In the field of health, especially in relation to public health policies, the apprehension of the meaning of the breadth of the law determines life and death issues, being an essential aspect to infer the degree of inclusion or exclusion of portions of the population to a care universal and free.
\end{abstract}

Keywords: right to health, social law, citizenship, universalization, social policy.

\section{Introdução}

O debate sobre os direitos sociais é um tema sempre presente no campo das políticas públicas contemporâneas. Torna-se mais significativa esta reflexão no momento que se assiste a um
Kera Yvoty: reflexiones sobre la cuestión social. Vol. 2, 2017, 56-66.

ISSN (impreso): 2519-7797

a Universidade Católica de Pelotas, Brasil.

Correspondencia a: veramrn@gmail.com

Cita:

Nogueira, V. M. R. (2017).

Vivencias de mujeres

Direito à saúde na sociedade contemporânea: convergência entre o público e o privado. Kera Yvoty: reflexiones sobre la cuestión social, 2, 72-82.

Recibido:

24 marzo 2017

Aceptado:

20 diciembre 2017 retrocesso em sua garantia, frente a uma ofensiva neoliberal, recrudescendo-se o individualismo e acirrando-se a competição e não a cooperação solidária que fortalece a coesão social. 
Parte-se do suposto que a compreensão dos direitos sociais e do direito à saúde ocorre em várias clivagens, $o$ que não significa que se autonomizam entre si, mas apresentam interfaces articuladas, que, dependendo do plano analítico, enriquecem o conhecimento sobre os mesmos, favorecendo tanto o ângulo do conhecimento como o das ações efetivas para sua garantia. Uma garantia que se materializa através de políticas públicas em decorrência do reconhecimento, pela sociedade, que os riscos sociais no mundo capitalista contemporâneo não tem como serem atendidos unicamente a partir do indivíduo, mas implicam em uma ação efetiva do Estado.

Não cabe entender a afirmação acima como uma defesa de padrões epistemológicos onde há a separação entre o pensar e o agir, mas como duas dimensões presentes em cada uma das abordagens, complementando e superando patamares compreensivos. De forma similar, convém observar que não se parte de uma idéia geral, ou universal, de justiça, ou ainda, da primazia do saber técnico ou popular sobre a questão. Desconsidera-se, também, qualquer aproximação formalista, na linha de uma ficção jurídica e alheia as condições do mundo da vida. Nesta linha, pensar os direitos importa em recorrer a sua dimensão política, que não descola da econômica e da jurídica, sendo imprescindível a sua articulação interna para se reduzir o risco de uma compreensão restrita ou parcial, desqualificando a totalidade do fenômeno analisado.

O trânsito entre os direitos, considerados em sua generalidade, para uma especificação de ordem setorial, como o direito à saúde, deve ser buscado no processo de expansão e diferenciação da ação política do Estado capitalista, no mesmo movimento de incorporação do atendimento dos bens de consumo coletivo, de acordo com Bayer e Leys, (1986) e tangenciando a posição de Castells (1978). No mesmo movimento analítico se apreende as transformações recentes sobre o direito à saúde, subsumidas as contratualidades presentes entre o Estado, capital e trabalho no final do século XX.

As contribuições de Bayer e Leys (1986) constituem um arcabouço analítico sugestivo para a abordagem do direito à saúde, delimitando sua apreensão nos Estados contemporâneos, ultrapassando análises conjunturais e com um possível viés tecnocrático e historicista.

Os autores sugerem que para se entender a constituição das políticas setoriais, deve-se retomar, brevemente, as atribuições e os papéis do Estado democrático de direito em países capitalistas, em decorrência de sua expansão e ampliação de funções. Três argumentos podem ser apontados para tais fenômenos: o Estado antecipando-se às necessidades de expansão do processo de acumulação capitalista; o Estadoassumindo como sua função o desenvolvimento de atividades próprias do setor privado; e a setorialização da política como mecanismo de fragmentação da participação política.

Embora não concordando com as afirmações de Bayer e Leys (1986), que os dois primeiros argumentos são reações a processos externos a atuação do Estado, a terceira interpretação é resgatada como referência significativa para ampliar a compreensão sobre o direito à saúde no capitalismo contemporâneo. Adiscordância funda-se em análises de Offe (1984, 1989), que entende que são movimentos que decorrem do próprio modo de ser do Estado liberal capitalista, compondo uma dinâmica que o associa e conforma às exigências do capital, sendo esta sua base de legitimidade.

Há, portanto, o reconhecimento que as relações sociais não ocorrem em um vazio, ou entre as pessoas, individualmente, mas que são mediadas por um complexo esquema institucional, coordenado pelo Estado, que modifica tanto a dimensão da produção quanto o plano das práticas políticas. Por essa razão, a setorialização da política no 
interior do Estado capitalista é vista

como conseqüência altamente benéfica, já que os mecanismos postos em ação pelo Estado para desenvolver suas novas atividades permitirão que ele exerça melhor o seu papel não apenas de controle unilateral mas também de mediatização escamoteadora da relação capital-trabalho. (Bayer \& Leys, 1986, p. 115)

Ocorre, de um lado, o provimento crescente de atividades ligadas à esfera da reprodução das condições de vida da população, sob a responsabilidade estatal, o que as desvincula de uma relação direta entre o capital e o trabalho, obscurecendo, assim, as condições de exploração do trabalhador. Esta desvinculação confere uma aparente neutralidade ao papel estatal, tornando-o supostamente independente da esfera da produção. Pode-se argumentar que não só isola o Estado do momento produtivo, como também as exigências da vida cotidiana, que são naturalizadas e interpretadas de per si.

Devido a esse movimento, as intervenções na esfera das políticas sociais se autonomizam da esfera da produção, situando-se como um mundo à parte, podendo suas falhas e inconsistências, serem explicadas, quando muito, como a incompetência do Estado. Ocorre, ainda, outro aspecto, que politicamente é mais sério, ou seja, tais ações podem ser atribuídas a um sentimento humanista, beneficente, unicamente de justiça social, de um problema da esfera administrativa ou, quando muito, relacionada aos aspectos redistributivos.

Uma segunda conseqüência, apontada pelos autores mencionados, é a tendência de concentração da participação política da população em aspectos setoriais, fragmentando tanto a densidade desta participação, como dificultando avaliar a legitimidade do Estado e desvelar a sua pretensa neutralidade.

Paralelamente, o argumento da condução dessas políticas não é diretamente político, mas sim técnico e aparentemente específico a cada área de política. Com isso, a questão da legitimação transforma-se em um somatório de argumentações técnicas específicas, reduzindo-a, portanto, a uma questão de eficiência. (Bayer \& Leys, 1986, p. 117)

Essa abordagem vem explicar o potencial ampliado de reivindicação, colocado em cena pelos movimentos sociais, na medida em que, quando adquirem maior densidade política questionam o aprofundamento da hegemonia do capital através do aparato técnico estatal.

Caberia aqui, incluir um parêntese e trazer a abordagem de Castells (1978), no sentido de complementar o queéfundamental para esse debate, ou seja, a apreensão da gênese dos direitos sociais particulares, especialmente o direito à saúde. Ao analisar a politização das questões urbanas, ainda na década de 1970, aponta que estas, enquanto problemas do quadro da vida, se apresentam como novas expressões da contradição capital-trabalho. Estas novas contradições, no entanto, não se assentam em uma contradição direta entre burguesia e classe operária, mas entre os interesses próprios da burguesia e os interesses do conjunto das camadas populares. Sobre os últimos incidem, de maneira perversa, os modos de organização da vida cotidiana impostos pela racionalidade do capital. Para Castells,

é justamente esse pluriclassismo das contradições urbanas que as torna estrategicamente fundamentais para uma transformação das relações sociais porque generaliza objetivamente as fontes de oposição à classe dominante na grande maioria do povo. (Castells, 1978, p. 146)

O processo político, no caso específico, partiria da articulação política das necessidades sociais, da organização dos interesses coletivos em torno de demandas concretas. Tal poderia vir a comprometer 
a ação aparentemente neutra do Estado, visto que as solicitações extrapolam a estrutura de classes e não teriam condições de serem administradas através do quadro institucional da política clássica'.

Continuando a argumentação central, as políticas setoriais se originariam, portanto da necessidade de administração estatal de determinadas atividades, exigências de ordem econômica, mas sendo intermediadas por estruturas políticas. A fragmentação das políticas setoriais favoreceria a legitimação do Estado, visto que as densidades políticas e a visibilidade maior são, flagrantemente obscurecidas, pela possibilidade do atendimento das demandas, via intervenção estatal.

Especificamente em relação à saúde, outros determinantes podem ser adicionados à interpretação da gênese do direito à saúde.

Uma delas se refere a apreender a política de saúde como derivada das "necessidades de reprodução ou até mesmo da própria constituição da força de trabalho e como resultado da constituição de interesses econômicos na área da saúde" (Bayer \& Leys, 1986, p. 119). Essa interpretação encontra-se presente na produção teórica de estudiosos vinculados à tradição marxista, qual subsidiou, em grande parte, propostas reformistas do período antecedente à crise fiscal do Estado brasileiro.

A construção do saber científico pode ser incorporada, não como uma explicação extemporânea e a-histórica, mas a partir da apreensão da construção parcelar das ciências, sob a inspiração cartesiana. A segmentação dos setores da vida e do humano permitiu, no momento da necessidade de uma intervenção deliberada, que os problemas, nas dimensões sociais e biológicas, sofressem

1 Ou seja, a relação direta entre a dominação política e a estrutura de classe, própria dos países capitalistas centrais, onde as posições são bem demarcadas e explícitas. uma intervenção fragmentada e pontual, onde cada disciplina ou saber científico, respondesse por um objeto ou aspecto único, desaparecendo a visão da totalidade do ser, de sua integralidade. Esse trato do mundo social e do mundo físico favoreceu os mecanismos de incorporação das demandas sociais pelo Estado, através de políticas sociais de corte setorial.

Outra interpretação é o potencial de controle, através das políticas de saúde, sobre a classe trabalhadora. Nesse campo, cabe retomar posição de Offe (1984), quando interpreta o papel das políticas de proteção ao trabalho favorecendo a transformação de mão de obra não assalariada em assalariada. Na saúde, esse argumento é poderoso, pois incorpora duas teses que devem ser assinaladas: o risco da incipiente sociedade de trabalho, e a interdição do acesso aos serviços de saúde por parte da classe trabalhadora em ascensão. Há que se observar que o nascimento da clínica, e dos cuidados médicos individuais, sempre foram conformados como uma atividade liberal $^{2}$, ou seja, a medicina manteve seu caráter estritamente privado até o final do século XIX. Não cabe entender essa observação como a não interferência estatal na saúde, pelo contrário, a literatura indica que a ação estatal sempre esteve articulada ao controle das grandes endemias e às medidas de higiene, com escassa regulação sobre a ação médica em si (Bernardelli, 1999).

A explicação para o acentuado enfoque nas políticas de saúde, e no direito à saúde, para sua ampliação ou sua redução, a partir da expansão, e posteriormente, da crise do Welfare State, articula as argumentações anteriores, ora sendo "a política vista como uma nova ocasião de lucro mundialista" (Castells, 1978, p. 161), ora como um custo que reduz o uso do

\footnotetext{
2 Essa situação parece ter sido distinta nas antigas civilizações, quando o poder e as práticas médicas integravam o próprio setor estatal ou situavam-se estritamente relacionadas a ele.
} 
fundo público em detrimento de seu uso pelo capital.

Uma última interpretação pode ser acrescentada às anteriores. De acordo com Bayer e Leys (1986), ao atuar de forma a obscurecer a contradição capital-trabalho, sua relevância para a constituição da forma tecnocrática de argumentação do Estado capitalista contemporâneo também é central: na medida em que for possível reduzir essa questão, tão diretamente ligada à vivência imediata das pessoas, aos parâmetros da discussão política tecnicizada, em menor grau passível de controle pelos dominados a partir de sua experiência concreta de vida. (Bayer \& Leys, 1986, p. 124).

As interpretações acima não indicam um padrão uniforme para a intervenção estatal, aplicado com o mesmo desenho em todos os países. Ao contrário, as exigências de ordem econômica e política vão conformando o direito à saúde, alterando seu conteúdo, seu alcance e os mecanismos acionados para sua garantia, tanto nos diversos países como, muitas vezes, no interior de cada país. As tendências de ajuste estruturais nas economias nacionais ampliam essa complexidade e diversidade, tornando a análise dos direitos sociais um exercício contínuo de articulação global - local.

Assim, a proposta de atenção à saúde é constantemente atualizada, incluindo as noções que correspondam a sua atualização para cada período e espaço. Portanto, o direito à saúde, longe de ser entendido como uma decorrência de abstratos ideais humanitários, de solidariedade universal, de moralidade ética, de justiça social, de necessidade básica articulada à sobrevivência, deve ser apreendido enquanto relacionado aos complexos e intrincados mecanismos de mediação de interesses, próprios do sistema capitalista em seu estágio atual.

As indicações acima explicam a alteração da hegemonia da Organização
Mundial da Saúde para o Banco Mundial, no que diz respeito à atenção à saúde. Esse processo de transposição do princípio de igualdade para o de equidade é iniciado em 1980 e explicitado claramente através do documento Investindo em saúde, publicado pelo Banco Mundial em 1993.

Melo e Costa (1994), ao analisar as estratégias das duas agências sobre o tópico em questão, apontam dois desafios enfrentados pelo Banco Mundial, que foram as bases sobre as quais se transformou o paradigma de equidade em saúde para equidade social. $\mathrm{O}$ primeiro foi entender a exigência de se pensar na sustentabilidade global, visto que os descuidos com o ecossistema poderiam significar o limite da vida. Curiosamente os analistas econômicos do Banco atribuem o possível desequilíbrio planetário ao aumento populacional desmedido, tendo mesmo alguns autores definido "como trade offe a escolha entre políticas governamentais que implicam incremento populacional e a manutenção do equilíbrio ambiental" (Melo \& Costa, 1994, p. x). A equidade seria difícil de se atingir futuramente em face da falência dos ecossistemas em decorrência do incremento populacional. Não tocam na questão de como a exploração desmedida na busca da ampliação de lucros, sem os cuidados devidos, se situa como uma das maiores agressões ao meio ambiente.

Um segundo desafio à relação da saúde como um direito universal como colocam ainda Melo e Costa (1994), se inscreve

em um amplo debate sobre as repercussões econômicas dos gastos incrementais em saúde nas economias capitalistas centrais. [...] Não raro a agenda do Banco Mundial apela para a diminuição do papel do Estado e para o fortalecimento do mercado para financiar e oferecer cuidados à saúde. [...] Prioriza doenças e programas específicos baseados em critérios de custo - efetividade. E advoga a ação do Estado na provisão de um pacote 
básico de serviços clínicos e de saúde pública. (p. 84)

Os gastos crescentes com a saúde, na perspectiva de um direito universal, levariam a uma forte redução nas economias capitalistas centrais e periféricas. A preocupação do Banco nos países centrais é com a redução e restrição na expansão do próprio capital, enquanto que nos países em desenvolvimento a preocupação com seu desempenho econômico se refere à capacidade de manter o compromisso em saldar a dívida externa.

A crise do Estado de Bem Estar e os mecanismos para correção dos rumos da acumulação capitalistas, tornam quase obrigatório abordar o direito a saúde, em suas alterações recentes, na sua relação com o fundo público. Esse eixo analítico ratifica e aprofunda a argumentação sobre os direitos sociais enquanto intrinsecamente relacionados à dimensão econômica.

A afirmação da estreita relação entre o direito à saúde e o fundo público decorre do processo identificado a partir dos anos 1970, do potencial das ações e serviços de saúde para, além da regulação política da força de trabalho, ser uma atividade crescentemente lucrativa. Abrange diversos setores produtivos, desde os produtores de insumos do complexo médico-hospitalar até as intervenções, via atendimento médico e hospitalar à população. Esse processo foi caracterizado como o de capitalização da medicina, em sua primeira etapa e, ao acentuar-se, foi nomeado de mercantilização da saúde (Negri \& Di Giovanni, 2001).

A superação dos modelos que possuíam como fundamento mobilizador e de sustentação o ideal de solidariedade, vêm sendo rapidamente superados pelo Consenso de Mercantilização da Saúde. O

\footnotetext{
3 Braga e Silva (2001) apontam e debatem, a partir da literatura sobre o Consenso de mercantilização da saúde, os argumentos e fundamentos deste eixo analítico.
}

crescimento das doenças crônicas devido ao envelhecimento da população, o descaso pela qualidade das ações desenvolvidas são apontados como responsáveis pelo trânsito mencionado.

Embora iluminem aspectos significativos, outras determinações podem ser aduzidas, especialmente as que derivam do crescente individualismo e diferenciação presentes nas sociedades atuais. Os imperativos macroeconômicos e as estratégias mercadológicas, utilizadas em larga escalam para transformar a saúde em um objeto corriqueiro de consumo contribuem, igualmente, paraa metamorfose na concepção de direito à saúde.

Nessa linha de raciocínio, a contribuição de Oliveira (1988) é significativa, pois permiteapreenderos nexos entre as dimensões políticas e econômicas no universo da saúde, que sempre foi colocada em um patamar diferenciado, mais referenciado aos ideais de solidariedade e benemerência e não de mercadoria.

Oliveira (1988), sistematicamente, vem discutindo o papel do fundo público e sua conseqüente relação com a esfera pública, a democracia e as políticas sociais ${ }^{4}$ como se demonstra a seguir ${ }^{5}$.

Contrariamente ao que ocorria no capitalismo concorrencial, quando o fundo público possuía um caráter expost, ou seja, surgia em seguida ao ciclo de reprodução do capital, hoje, o fundo público ocupa uma posição ex-ante das condições de reprodução dos capitais particulares e das condições de reprodução da vida social. Como afirma Oliveira, "ele é a referência pressuposta principal, que no jargão de hoje, sinaliza as possibilidades da

\footnotetext{
4 Oliveira discute o fundo público em relação às políticas sociais, não se detendo particularmente na saúde, mas o patamar explicativo e a riqueza de sua argumentação contribuem, em muito, para entender a situação atual da política de saúde nas reformas em curso nos países capitalistas.

5 A argumentação a seguir é retirada de Francisco de Oliveira (1988), em seu artigo, O surgimento do antivalor, no Dossiê Welfare State.
} 
reprodução" (1988, p. 9).

A análise, sob o olhar da reprodução da força de trabalho, ressalta sua contribuição para a ampliação do salário indireto, libertando o salário direto para outros itens dos gastos domésticos e alimentando o consumo de massa, tendo como conseqüência o crescimento dos mercados de bens de consumo duráveis ${ }^{6}$. Nesse raciocínio o padrão de financiamento público do Welfare State transformou os fundamentos da categoria do valor como ponto central da reprodução tanto do capital como da força de trabalho. Transformouse, o padrão de financiamento, em um locus público de discussão, um espaço de construção de regras consensuais e estáveis (porque previsíveis), ou seja, uma esfera pública, onde a competição capitalista é limitada pelas próprias regras ali definidas. Continuando sua rigorosa argumentação, Oliveira indica as conseqüências teóricas desse padrão de financiamento para o campo marxista, repondo, especialmente, o problema clássico da tendência declinante da taxa de lucro e os limites do próprio sistema capitalista, que permanecem na negação de suas categorias reais, o capital e a força de trabalho. Considera que as alterações decorrentes do uso do fundo público transformam-no em um antivalor, "menos no sentido de que o sistema não mais produz valor, e mais no sentido de que os pressupostos da reprodução do valor contêm, em si, mesmos, os elementos mais fundamentais de sua negação" (Oliveira, 1988, p. 19).

O percurso teórico de Francisco de Oliveira (1988, p. 19) conduz a indicação de que o Estado de Bem Estar e suas instituições não são o "horizonte intransponível", que, para "além dele,

6 Segundo ainda o mesmo autor é esse padrão crescente de financiamento público que está provocando o continuado déficit nos países industrializados e, portanto, é esse padrão que está em crise e não a intervenção estatal. bate latente, um modo social de produção superior" e que o manejo do fundo público é a pedra de toque do futuro capitalista. Alerta que houve uma alteração na relação social de produção e que no Welfare State o que ocorreu foi uma alteração nas condições de produção e consumo - do lado da força de trabalho - e das condições de circulação - do lado do capital. Ou, dito de outra forma, as relações de produção continuaram praticamente as mesmas do capitalismo concorrencial, entretanto, as formas de distribuição e de circulação do capital, que tem conseqüências nas outras esferas da vida social, sofreram mudanças significativas.

A resultante desse percurso instituiu uma esfera pública, ou uma economia de mercado socialmente regulada, nos marcos da democracia, alterando o paradigma liberal clássico. $\mathrm{O}$ aspecto fundamental na construção da esfera pública (e os desdobramentos democráticos que impõe), é que, não só regulamenta todas as áreas conflitivas da reprodução social 7 , como essa regulação decorre:

do imbricamento do fundo público na reprodução social em todosossentidos, mas, sobretudo criando medidas que medem o próprio imbricamento acima das relações privadas. A tarefa da esfera pública é, pois, a de criar medidas, tendo como pressupostos as diversas necessidades da reprodução social, em todos os sentidos. (Oliveira, 1988, p. 22)

Ocorre, assim, que a atenção às necessidades de reprodução da força de trabalho não mais se constitui em pressuposto para implantação de serviços e bens que contribuam, unicamente, para a reprodução do capital. É nesse âmbito que deve ser discutido o direito à saúde.

\footnotetext{
7 Se permanecesse unicamente com esse caráter, seria quase inócuo seu desempenho, limitando-se a expandir as regras da convivência privada para uma área pública, e que é o que o Direito usualmente faz.
} 
A segunda decorrência, da argumentação de Oliveira (1988, p. 23), se refere à relação entre Estado e sociedade civil. Essas relações, queantes da construção da esfera pública, impunham uma "irredutibilidade entre Estado e Sociedade Civil" tomam outro feitio, do qual podem ser retomadas algumas peculiaridades: as relações não se configuram mais um puro jogo de forças para a anulação de um dos pólos de interesse; garante-se o respeito pela alteridade de interesses, ou seja, admite-se que, embora não havendo concordância, que os direitos dos outros são legítimos; os interesses dos diferentes grupos dizem respeito a reprodução social em grande escala e não podem mais serem medidos pela acumulação privada do capital.

A forma política mais adequada para construção da esfera pública é o espaço da democracia participativa,

no qual, além das classes e grupos diretamente interessados, intervêm outras classes e grupos, constituindo o terreno do público, que está acima do privado. [...] Nesse sentido, longe da desaparição das classes sociais, tanto a esfera pública como seu corolário, a democracia representativa, afirmam as classes sociais como expressões coletivas e sujeitos da história. (Oliveira, 1988, p. 23)

Para além do plano econômico, e enveredando para a ação política, a qualidade e o vetor da representação ampliaram sobremaneira o papel dos partidos políticos, que passam a não ser mais unicamente identificados com as classes sociais, mas como representantes de classes, com competência para processar as novas formas de relações de alteridade, que se fazem presentes no jogo democrático. As relações de alteridade e o jogo de interesses presentes se processam em uma perspectiva de resultados e não apenas de pressupostos, o que exige uma capacidade de articulação de interesses e não mais a imposição da vontade geral em termos rousseaunianos, destacando-se a relevância das classes médias nessa interpolação de conflitos. Assim, a saúde passa a fazer parte da busca desse resultado, que interessa, indistintamente, a reprodução do capital e da força de trabalho, sendo que a busca de investimentos para garantia, e para expansão dos direitos nessa área, aglutina interesses que se transformam em forças políticas.

A organização dos interesses, nas sociedades contemporâneas, dada sua complexidade, não se restringe às clássicas representações via partidos políticos ou ação sindical, expressões políticas do confronto capital-trabalho, nos estágios concorrenciais da acumulação capitalista.

A pluralidade de instituições mediadora, segundo Oliveira (2002), constitui "a armadura material dos direitos da cidadania”. Contrapondo-se ao ideário liberal, que pensa no individuo isolado exercendo sua autonomia, afirma, categoricamente, que o individuo se relaciona com os demais (com exceção do individuo no plano privado), através de instituições que dão sustentação e enquadram a cidadania. Deve-se recordar como as instituições, enquanto espaços políticos, representam interesses organizados, sendo perpassadas pela construção de consensos que sustentam as posições e as escolhas feitas.

Ao se tratar das instituições e respectivas mediações, a aproximação conceitual sobre os direitos sociais, e especialmente o direito à saúde, se relaciona ao direito enquanto instituição jurídica, utilizada aqui nos dois sentidos que lhe atribuem Dallari e Fortes (1997), apoiandose em Reale:

o direito, um sistema de normas que regulamenta o comportamento dos homens em sociedade. Muitas vezes se emprega o direito em um sentido axiológico, como sinônimo de justiça, e muitas outras em sentido subjetivo. [...] Na reivindicação do direito à saúde, o termo é empregado em seu sentido 
subjetivo. Todavia, a referência à regras de direito vista por dentro implica necessariamente a compreensão do direito como regras do comportamento humano em sociedade. (Dallari \& Fortes, 1997, p. 188)

Ainda que o argumento tenha uma carga normativa bastante acentuada, não se pode desconhecer sua importância, pois influencia, positivamente, as deliberações a respeito da responsabilidade de cada um e do Estado em sua garantia.

A autora reconhece, na esteira de autores que relacionam o direito à saúde ao desenvolvimento do sistema capitalista de produção, que foi a urbanização e o processo de industrialização, com suas conseqüentes manifestações de ordem política que impuseram, ao Estado, o provimento das ações de saúde, especificamente em saneamento e nos códigos sanitários.

Outra vertente analítica aprecia o direito à saúde tendo como fundamento os ideais liberais da Revolução Francesa. A igualdade entre os homens impediria ações caritativas, resquícios de uma ordem social considerada ultrapassada.

Ainda no plano jurídico, outra distinção, ou emoutrostermos, outra possível antinomia se faz presente: a contraposição entre o direito individual e o coletivo, o social. No plano individual, a garantia do direito à saúde envolve a liberdade em várias situações, como por exemplo, o tipo de tratamento, a relação com o meio ambiente, as condições de trabalho. A liberdade individual, assim, implicaria escolhas entre distintas alternativas. Entretanto, sinalizam Dallari e Fortes (1997),

é óbvio, então, que a efetiva liberdade necessária ao direito à saúde enquanto direito subjetivo depende do grau de desenvolvimento do Estado. De fato, unicamente no Estado desenvolvido sócio-econômica e culturalmente o indivíduo é livre para procurar um completo bem-estar físico, mental e social e para, adoecendo, participar do estabelecimento do tratamento.

No plano sócio-jurídico pode-se avaliar o direito à saúde em dois aspectos. No primeiro, as exigências aos indivíduos, face ao coletivo, obrigando-os a submissão às normas jurídicas, como a vacinação, ao tratamento, ao isolamento em casos de algumas doenças infecto-contagiosas, à destruição de produtos impróprios para o consumo, o controle do meio ambiente e do ambiente de trabalho. No segundo, a garantia da oferta de cuidados da saúde a todos que deles necessitam, o que corresponde ao ideal de igualdade, o que por sua vez se submete ao pleno desenvolvimento do Estado democrático de direito.

Dallari e Fortes (1997, p. 190), chamam a atenção para a tensão entre liberdade e igualdade ao se tratar do direito à saúde. $\mathrm{Na}$ esfera jurídica, esse direito, ao apropriar-se da liberdade e da igualdade "caracteriza-se pelo equilíbrio instável desses valores. [...] Os homens sempre tiveram a consciência de que para nada serve a igualdade sob o jugo do tirano e a liberdade só existe entre iguais". Embora iluminem aspectos essenciais, a argumentação acima deve forçosamente incluir a relação entre Estado-sociedade-indivíduo. Embora o individualismo permaneça como principal característica dos direitos humanos, enquanto direitos subjetivos, as opões políticas de cada sociedade diferenciam os papéis assumidos pelo Estado. Em outros termos, nas sociedades liberais o papel estatal se distingue, nitidamente, do papel do indivíduo, havendo sempre a preocupação em resguardar os direitos desse frente ao Estado. Como conseqüência, sua interferência se resume na garantia dos direitos negativos, na preservação da ordem, das leis e, no plano da saúde, quando muito, na saúde pública. Em sociedades de perfil socialistas, sociais democratas ou mesmo com tendências políticas mais 
progressistas, há o reconhecimento, no plano da lei, de direitos de titularidade coletiva, onde há a interferência estatal em aspectos condizentes, inclusive, aos direitos individuais e também a indicação da igualdade da cidadania face às questões sanitárias - o direito social à saúde.

Ainda nesse campo, a observação de Schwartz (2001), seguindo uma tradição renovadora que vem surgindo na ala dos estudiosos de direito ${ }^{8}$, é sumamente oportuna.

Ao estabelecer, com rigorosos fundamentos teóricos e conceituais, a conexão existente entre o direito à saúde e o Estado Democrático de Direito ${ }^{9}$, evidencia ser, essa conexão, vital para sua garantia. O Estado Democrático de Direito supera o império da lei típico do Estado de Direito. "É uma modalidade estatal que procura transformar a realidade, onde a lei passa a ser um instrumento fundamental de mudança do status quo, fundamentada e baseada em vetores axiológicos tais como os direitos fundamentais do homem" (Schwartz, 2001, p. 49).

Na concepção de Schwartz, que não deixa de ser uma crítica rigorosa aos padrões jurídicos, usualmente fundamentados no dito império da lei, se pode vislumbrar uma utopia, de transformar o direito em uma ferramenta para um determinado tipo de justiça social, servindo para alterar relações

8O ensino ea prática do Direitovêm sendo adensados, com o que vem se denominando uma nova cultura do direito, a qual implica em superar o formalismo e a dogmática jurídica, alicerçando-se nas condições reais da existência. Tal significa um novo olhar para a legalidade e a legitimidade. A produção teórica de estudiosos do Direito, em algumas Universidades do Rio Grande do Sul, espelha essa inovação.

9 O Estado Democrático de Direito obedece aos seguintes princípios: constitucionalismo (Constituição como garantia jurídica), organização democrática da sociedade (com incorporação de novos elementos como as Organizações Não Governamentais - ONGs), sistema de direitos fundamentais individuais e coletivos (Constituição garantindo efetivação de ambos), justiça social (elemento de correção de desigualdades sociais), igualdade, divisão de poderes ou funções, legalidade e segurança e certezas jurídicas. que contrariem o ideal de bem estar e a qualidade de vida instituído no texto constitucional.

Depreende esse autor, que a relação entre Estado Democrático de Direito e a saúde, éum conceito básico para a efetivação desse direito. Schwartz (2001), destaca outro ponto relevante relacionado a sua incursão na teoria das gerações de direitos, seguindo a classificação de Norberto Bobbio (1992). No seu entendimento, o direito à saúde, ou seu equivalente, o direito à vida, se configura como de primeira geração, enquanto particular, absoluto e caracterizado pela sua titularidade individual. É uma garantia irrenunciável, intransferível, indisponível e extrapatrimonial (Schwartz, 2001).

$\mathrm{Na}$ medida em que sua garantia importa em ações positivas do Estado, pode ser considerado de segunda geração, na ordem dos direitos sociais. A igualdade prevista para a garantia da saúde, como uma das conquistas da contemporaneidade ocorre na maior parte dos países estando prevista, também, nos estatutos dos Organismos Internacionais de Fins Humanitários, como a Organização das Nações Unidas, incluindo a Organização Mundial da Saúde.

Atribui ao direito à saúde o estatuto de direito de terceira geração, pois pode ser apreendido na esteira dos direitos transindividuais, também nomeados como coletivos ou difusos. Essa afirmação se baseia no fato, de inúmeras vezes, não se poder atribuir titularidade ao direito, sendo, portanto, patrimônio de um grupo, ou até da humanidade, no caso da preservação ambiental.

Como um direito de quarta geração, se vincula ao progresso da genética, conectado à biotecnologia e a bioengenharia, situação em que a reflexão sobre sua garantia é circunscrita, menos pelo fator técnico, e mais pelo aspecto ético.

Schwartz (2001) considera, com uma base ainda empírica, que o direito à saúde apresenta atributos que o qualificam como um direito de quinta-geração, pois 
o não acesso aos recursos da cibernética incidiria sobre a qualidade de vida, e, por conseguinte, na saúde. Afirma ainda, que a possibilidade de consultas e esclarecimentos on line, sobre a saúde, lhe atribuem essa qualificação.

Além da matriz jurídica, política e econômica, o direito à saúde vem sendo, atualmente reposto pela bioética. Talvez seja importante precisar, mesmo que de forma apenas indicativa, os termos dessa discussão e seu enfoque.

Não há uma posição consensual sobre as origens, tanto do termo bioética como de sua aplicação à área da saúde. As referências indicam que a bioética, como movimento organizado e sistematizado, estabeleceuse nas décadas de 1970 e 1980, nos países ocidentais, com o propósito de discutir as dimensões morais da ciência, da vida e do cuidadoà saúde. As inovações nas pesquisas com seres humanos e a biotecnologia repuseram no debate a dimensão moral e filosófica, com um olhar particular sobre a dignidade humana, o cuidado com o ser vivo e a qualidade de vida, particular, global e planetária.

Concluindo, o direito à saúde é um item complexo da agenda política e da agenda governamental e o debate, ou seja, o confronto sobre seu alcance e seu conteúdo, se subsume a concepção de saúde adotada para direcionar a sua institucionalidade e sua constitucionalidade. Os interesses presentes e a capacidade organizativa dos diferentes grupos darão o tom do debate e, mais do que isso, viabilizarão a inclusão e efetivação do direito à saúde com um perfil onde a democracia e a universalidade encontrarão abrigo amplo ou um espaço extremamente reduzido.

\section{Referências Bibliográficas}

Bayer, G. F. \& Leys, H. R. (1986). Saúde enquanto questão politicamente intermediada. Serviço Social e Sociedade, 22, 108-125.

Bernaderlli. J. C. (1988). La reglamentación de la medicina/ Regulation of medicine.
Anais de Otorrinolaringologia, 4, 227232.

Bobbio, N. (1992). A era dos direitos. Rio de Janeiro: Editora Campus/Elsevier.

Braga, J. C. S. \& Silva, P. L. B. (2001). A mercantilização possível e as políticas públicas inadiáveis: estrutura e dinâmica do setor saúde no Brasil (pp.19-42). In B. Negri \& G. Di Giovanni (Eds.), Brasil: radiografia da saúde. Instituto de Economia/UNICAMP.

Castells, M. (1978). Crise do Estado, consumo coletivo e contradições urbanas (pp. 145-170). In: N. Poulantzas (Ed.), A crise do estado. Lisboa: Editora Moraes.

Dallari, S. G \& Fortes, P. A. C., 1997. Direito sanitário: inovação teórica e novo campo de trabalho. In S. Fleury (Ed.), Saúde e Democracia: a Luta do CEBES. São Paulo: Editora Lemos.

Melo, M. A. B. C., Costa, N. R. (1994). Desenvolvimento Sustentável, ajuste estrutural e política social: as estratégias da OMS/OPS e do Banco Mundial para a atenção à saúde. Planejamento $e$ Políticas Públicas, (11), 49-108.

Negri, B., Di Giovanni, G. (Eds.). (2001). Brasil: radiografia da saúde. Campinas: Instituto de Economia/UNICAMP.

Offe, C. (1984). Problemas estruturais do Estado capitalista. Rio de Janeiro: Tempo Brasileiro.

Oliveira, F. (1988). O surgimento do antivalor. Novos Estudos, São Paulo, (22), 8-28.

Oliveira, F. (2002). O que é formação para a cidadania? Entrevista realizada por Sílvio Caccia Bava, em 1999. Recuperado de http://www.dhnet.org. $\mathrm{Br} /$ textos/coliveira.htm

Schwartz, G. (2001). Direito à Saúde: efetivação em uma perspectiva sistêmica. Porto Alegre: Livraria do Advogado. 